\title{
Evaluation of the efficacy of a trivalent vaccine mixture against a triple challenge with Mycoplasma hyopneumoniae, PCV2, and PRRSV and the efficacy comparison of the respective monovalent vaccines against a single challenge
}

Taehwan Oh, Kee Hwan Park, Siyeon Yang, Jiwoon Jeong, Ikjae Kang, Changhoon Park and Chanhee Chae* (D)

\begin{abstract}
Background: The objective of this study was to assess the efficacy of a trivalent vaccine mixture and compare it to the respective monovalent vaccines against Mycoplasma hyopneumoniae, porcine circovirus type 2 (PCV2), and porcine reproductive and respiratory syndrome virus (PRRSV).

Results: Pigs that were triple challenged with M. hyopneumoniae, PCV2, and PRRSV following vaccination with the trivalent vaccine mixture exhibited a significantly better growth performance when compared to unvaccinated and challenged pigs. A statistical difference was not found when comparing pig populations which were vaccinated with the trivalent vaccine followed by a triple challenge and pigs vaccinated with monovalent $M$ hyopneumoniae vaccine followed by mycoplasmal single challenge in the following areas: $M$. hyopneumoniae nasal shedding, the number of $M$. hyopneumoniae-specific interferon- $\gamma$ secreting cells (IFN- $-\mathrm{SC}$ ), and mycoplasmal lung lesion scores. Pigs vaccinated with the trivalent vaccine mixture followed by a triple challenge resulted in a similar reduction of PCV2 viremia, an increase in the number of PCV2-specific IFN- $\gamma-S C$ and reduction in interstitial lung lesion scores when compared to pigs vaccinated with a PCV-2 vaccine and challenged with PCV2 only. Lastly, there was a significant difference in the reduction of PRRSV viremia, an increase in PRRSV-specific IFN- $\gamma$-SC and a reduction of interstitial lung lesion scores between pigs vaccinated with the trivalent vaccine mixture followed by a triple challenge and pigs vaccinated with a monovalent PRRSV vaccine followed by PRRSV challenge only.

Conclusion: The trivalent vaccine mixture was efficacious against a triple challenge of $M$. hyopneumoniae, PCV2, and PRRSV. The trivalent vaccine mixture, however, did not result in equal protection when compared against each respective monovalent vaccine, with the largest vaccine occurring within PRRSV.
\end{abstract}

Keywords: Mycoplasma hyopneumoniae, Porcine circovirus type 2, Porcine reproductive and respiratory syndrome virus, Porcine respiratory disease complex

\footnotetext{
* Correspondence: swine@snu.ac.kr

College of Veterinary Medicine, Department of Veterinary Pathology, Seoul

National University, Gwanak-ro 1, Gwanak-gu, Seoul 08826, Republic of Korea
}

(c) The Author(s). 2019 Open Access This article is distributed under the terms of the Creative Commons Attribution 4.0 International License (http://creativecommons.org/licenses/by/4.0/), which permits unrestricted use, distribution, and reproduction in any medium, provided you give appropriate credit to the original author(s) and the source, provide a link to the Creative Commons license, and indicate if changes were made. The Creative Commons Public Domain Dedication waiver (http://creativecommons.org/publicdomain/zero/1.0/) applies to the data made available in this article, unless otherwise stated. 


\section{Background}

Porcine respiratory disease complex (PRDC) is a disease that predominately affects growing to finishing pigs between the ages of 14 to 20 weeks. This is commonly referred to as the '18-week wall' in modern commercial pig production. There are multiple factors that contribute to PRDC including multiple viral and bacterial infections, environmental conditions, and management practices. Clinical signs are characterized by slow and uneven growth, decreased feeding efficiency, anorexia, fever, cough, and dyspnea $[1,2]$.

Currently, PRDC is one of the biggest health concerns to the Asian swine industry. The etiological agents associated with PRDC may vary between different geographic regions, but in Asia, Mycoplasma hyopneumoniae, porcine circovirus type 2 (PCV2), and porcine reproductive and respiratory syndrome virus (PRRSV) are the primary pathogens which cause the majority of the PRDC cases resulting in devastating economic losses [1]. Most Asian swine producers control PRDC by use of preventative vaccines rather than antibiotics. Combination vaccines are preferred in order to reduce pig stress and to decrease labor cost. A trivalent vaccine mixture (3FLEX, Boehringer Ingelheim Vetmedica, St. Joseph, Missouri, USA) against $M$. hyopneumoniae, PCV2, and PRRSV has been licensed in many Asian countries to control PRDC. However, there is concern from some swine producers that this trivalent vaccine mixture may be less effective compared to the respective monovalent vaccines currently available because of possible interferences among the mixed antigens. In this study, we decided to evaluate the efficacy of this trivalent vaccine mixture (3FLEX, Boehringer Ingelheim Vetmedica) against a triple challenge of $M$. hyopneumoniae, PCV2, and PRRSV and compare it to the efficacy of the respective monovalent vaccines. Clinical, immunological, microbiological, and pathological parameters were chosen for evaluation.

\section{Results}

\section{Clinical observation}

The mean scores for respiratory disease were significantly higher $(P<0.05)$ in pigs from the UnVac/Ch3 group when compared to the Vac3FLEX/Ch3, VacMhp/ ChMhp, UnVac/ChMhp, and UnVac/UnCh groups from -7 to $28 \mathrm{dpc}$ (Fig. 1a) and Vac3FLEX/Ch3, VacPCV2/ ChPCV2, UnVac/ChPCV2, and UnVac/UnCh groups from -7 to $28 \mathrm{dpc}$ (Fig. 1b). The mean respiratory scores were significantly higher $(P<0.05)$ in pigs from the UnVac/Ch3 and UnVac/ChPRRSV groups compared to the Vac3FLEX/Ch3, VacPRRS/ChPRRSV, and UnVac/ UnCh groups at $-7 \mathrm{dpc}$ (Fig. 1c).

\section{Average daily weight gain}

No statistical difference was observed in the average body weight (mean \pm standard deviation) among the 9 groups at 21 days of age which was the start of the study; Vac3FLEX/Ch3 $(n=20,6.42 \mathrm{Kg} \pm 0.54), \quad$ VacMhp/ ChMhp $(n=20,6.41 \mathrm{Kg} \pm 0.52)$, VacPCV2/ChPCV2 $(n=$ 20, $6.41 \mathrm{Kg} \pm 0.49)$, VacPRRS/ChPRRSV $(n=20,6.42$ $\mathrm{Kg} \pm 0.45), \mathrm{UnVac} / \mathrm{Ch} 3(n=10,6.41 \mathrm{Kg} \pm 0.51), \mathrm{UnVac} /$ ChMhp $(n=10,6.43 \mathrm{Kg} \pm 0.47)$, UnVac/ChPCV2 ( $n=10$, $6.41 \mathrm{Kg} \pm 0.45), \quad$ UnVac/ChPRRSV $(n=10,6.42 \mathrm{Kg} \pm$ $0.45)$ and $\mathrm{UnVac} / \mathrm{UnCh}(n=10,6.42 \mathrm{Kg} \pm 0.49)$. The overall ADWG (from 21 to 84 days old) of pigs from the Vac3FLEX/Ch3, VacMhp/ChMhp, VacPCV2/ChPCV2, VacPRRS/ChPRRSV, UnVac/ChMhp, UnVac/ChPCV2, UnVac/ChPRRSV, and UnVac/UnCh groups was significantly higher $(P<0.05)$ when compared to the UnVac/ Ch3 group (Table 1).

\section{Quantification of 3 pathogens}

Prior to challenge, no genomic copies of $M$. hyopneumoniae, PCV2, and PRRSV were detected in any of the pigs from all 9 groups. Pigs in the Vac3FLEX/Ch3 and VacMhp/ChMhp groups had significantly less $(P<0.05)$ M. hyopneumoniae genomic copies in their nasal swabs compared to the UnVac/Ch3 and UnVac/ ChMhp groups at 7 and 14 dpc. Pigs in the VacMhp/ ChMhp group had a significantly lower $(P<0.05)$ number of $M$. hyopneumoniae genomic copies in their nasal swabs compared to the UnVac/Ch3 group at 28 dpc (Fig. 2a).

Pigs from the Vac3FLEX/Ch3 and VacPCV2/ChPCV2 groups had a significantly lower $(P<0.05)$ number of genomic copies of PCV2 in their blood compared to the UnVac/Ch3 and UnVac/ChPCV2 groups at 7, 14, and 28 dpc. Pigs from the UnVac/ChPCV2 group had a significantly lower $(P<0.05)$ number of genomic copies of PCV2 in their blood compared to the UnVac/Ch3 group at 7 and $14 \mathrm{dpc}$ (Fig. 2b).

The Vac3FLEX/Ch3 and VacPRRS/ChPRRSV groups had a significantly lower $(P<0.05)$ number of genomic copies of PRRSV in their blood compared to the UnVac/Ch3 and UnVac/ChPRRSV groups at $-7,0,7$, and $14 \mathrm{dpc}$. The VacPRRS/ChPRRSV group had a significantly lower $(P<0.05)$ number of genomic copies of PRRSV in their blood compared to the UnVac/Ch3 group at $28 \mathrm{dpc}$. The UnVac/ChPRRSV group had a significantly lower $(P<0.05)$ number of genomic copies of PRRSV in their blood compared to the UnVac/Ch3 group at $0 \mathrm{dpc}$. No genomic copies of PRRSV were detected in any of the pigs from $\mathrm{UnVac} / \mathrm{UnCh}$ group (Fig. 2c). No genomic copies of $M$. hyopneumoniae, PCV2, and PRRSV were detected in any of the pigs from the UnVac/UnCh group. 


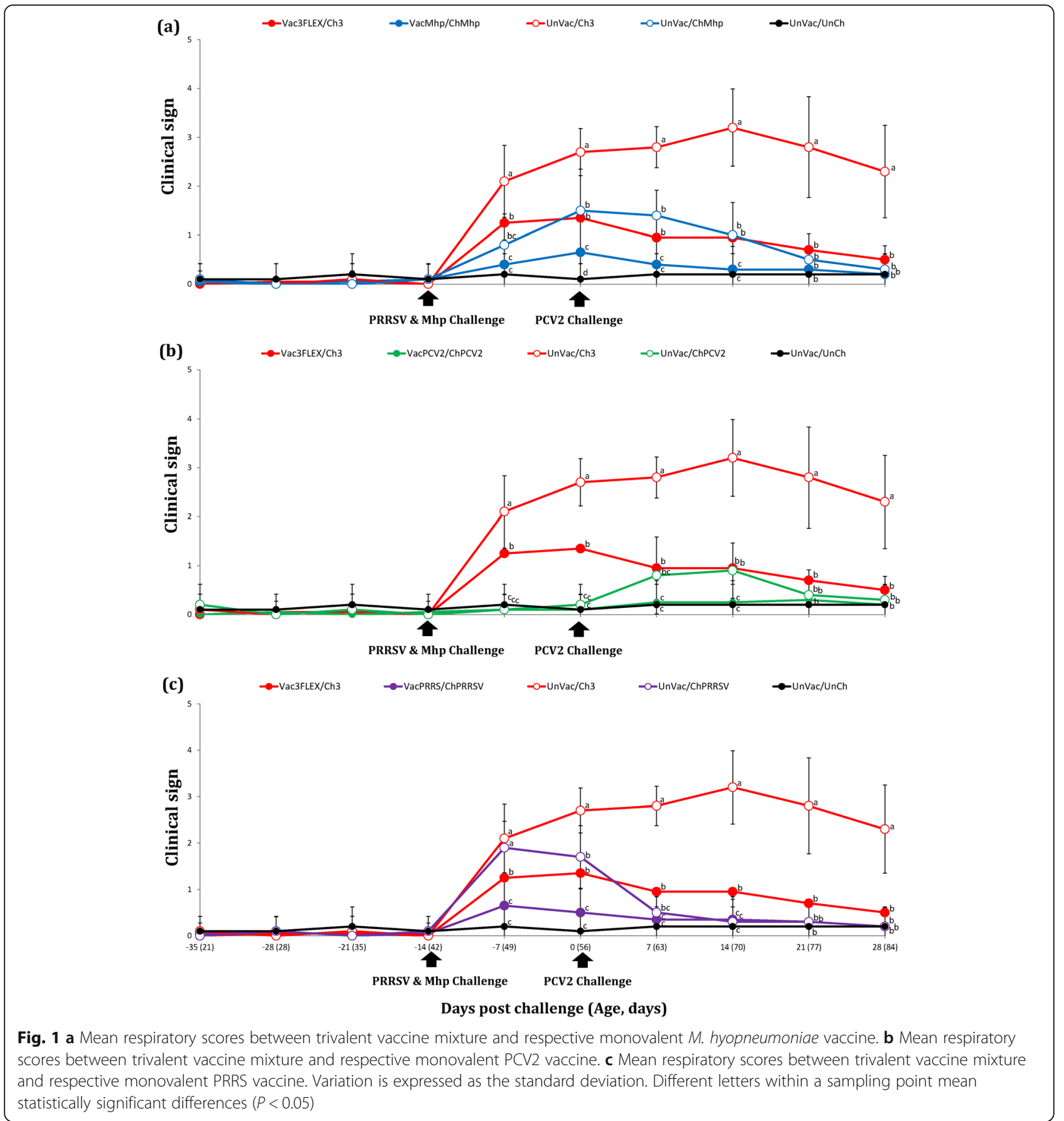

\section{Serology}

Antibody response against $M$. hyopneumoniae was assessed with ELISA. Pigs in the Vac3FLEX/Ch3 and VacMhp/ChMhp groups had a significantly higher $(P<$ $0.05)$ M. hyopneumoniae ELISA S/P ratio compared to the UnVac/Ch3 and UnVac/ChMhp groups at $0 \mathrm{dpc}$. Pigs in the Vac3FLEX/Ch3 group also had a significantly higher $(P<0.05) M$. hyopneumoniae ELISA S/P ratio compared to the UnVac/Ch3 group at $28 \mathrm{dpc}$ (Fig. 3a).
Pigs from the Vac3FLEX/Ch3 and VacPCV2/ChPCV2 groups had a significantly higher $(P<0.05)$ PCV2 ELISA titers compared to the UnVac/Ch3 and UnVac/ChPCV2 groups between -14 to $28 \mathrm{dpc}$ (Fig. 3b).

The Vac3FLEX/Ch3 and VacPRRS/ChPRRSV groups had a significantly higher $(P<0.05)$ PRRSV ELISA S/P ratio compared to the $\mathrm{UnVac} / \mathrm{Ch} 3$ and UnVac/ ChPRRSV groups from -14 to $28 \mathrm{dpc}$. The UnVac/ ChPRRSV group had a significantly higher $(P<0.05)$ 
Table 1 Average daily weight gain (ADWG) in trivalent vaccine mixture and respective monovalent vaccines

\begin{tabular}{llll}
\hline Groups & \multicolumn{2}{l}{ Average Daily Weight Gain (grams/day/pig) } & \\
\cline { 2 - 4 } & $21-56$ & $56-84$ & $21-84$ \\
\hline Vac3FLEX/Ch3 & $367.29 \pm 23.18^{\mathrm{ab}}$ & $654.29 \pm 57.30^{\mathrm{a}}$ & $494.84 \pm 30.77^{\mathrm{a}}$ \\
VacMhp/ChMhp & $375.71 \pm 25.50^{\mathrm{a}}$ & $663.93 \pm 60.33^{\mathrm{a}}$ & $503.81 \pm 27.95^{\mathrm{a}}$ \\
UnVac/Ch3 & $343.43 \pm 13.46^{\mathrm{b}}$ & $537.86 \pm 36.51^{\mathrm{b}}$ & $429.84 \pm 18.90^{\mathrm{b}}$ \\
UnVac/ChMhp & $370.57 \pm 25.31^{\mathrm{ab}}$ & $643.57 \pm 63.39^{\mathrm{a}}$ & $491.91 \pm 28.79^{\mathrm{a}}$ \\
UnVac/UnCh & $386.57 \pm 25.56^{\mathrm{a}}$ & $667.50 \pm 68.95^{\mathrm{a}}$ & $511.43 \pm 32.98^{\mathrm{a}}$ \\
Vac3FLEX/Ch3 & $367.29 \pm 23.18^{\mathrm{ab}}$ & $654.29 \pm 57.30^{\mathrm{a}}$ & $494.84 \pm 30.77^{\mathrm{a}}$ \\
VacPCV2/ChPCV2 & $377.43 \pm 28.30^{\mathrm{a}}$ & $664.29 \pm 71.48^{\mathrm{a}}$ & $504.92 \pm 27.92^{\mathrm{a}}$ \\
UnVac/Ch3 & $343.43 \pm 13.46^{\mathrm{b}}$ & $537.86 \pm 36.51^{\mathrm{b}}$ & $429.84 \pm 18.90^{\mathrm{b}}$ \\
UnVac/ChPCV2 & $376.57 \pm 24.12^{\mathrm{a}}$ & $649.29 \pm 64.66^{\mathrm{a}}$ & $497.78 \pm 32.30^{\mathrm{a}}$ \\
UnVac/UnCh & $386.57 \pm 25.56^{\mathrm{a}}$ & $667.50 \pm 68.95^{\mathrm{a}}$ & $511.43 \pm 32.98^{\mathrm{a}}$ \\
Vac3FLEX/Ch3 & $367.29 \pm 23.18^{\mathrm{abc}}$ & $654.29 \pm 57.30^{\mathrm{a}}$ & $494.84 \pm 30.77^{\mathrm{a}}$ \\
VacPRRS/ChPRRSV & $375.57 \pm 26.78^{\mathrm{ab}}$ & $660.71 \pm 62.28^{\mathrm{a}}$ & $502.30 \pm 29.15^{\mathrm{a}}$ \\
UnVac/Ch3 & $343.43 \pm 13.46^{\mathrm{c}}$ & $537.86 \pm 36.51^{\mathrm{b}}$ & $429.84 \pm 18.90^{\mathrm{b}}$ \\
UnVac/ChPRRSV & $354.57 \pm 25.00^{\mathrm{bc}}$ & $645.36 \pm 59.38^{\mathrm{a}}$ & $483.81 \pm 30.49^{\mathrm{a}}$ \\
UnVac/UnCh & $386.57 \pm 25.56^{\mathrm{a}}$ & $667.50 \pm 68.95^{\mathrm{a}}$ & $511.43 \pm 32.98^{\mathrm{a}}$ \\
\hline
\end{tabular}

Different letters mean statistically significant differences within 5 groups $(P<0.05)$

PRRSV ELISA S/P ratio compared to the UnVac/Ch3 group at 7,14 , and $28 \mathrm{dpc}$ (Fig. 3c). No antibodies against $M$. hyopneumoniae, PCV2, and PRRSV were detected in any of the pigs from UnVac/UnCh group (Fig. 3c). All pigs from all 9 groups were negative for influenza A virus antibodies.

\section{Interferon- $\gamma$ secreting cells}

For $\mathrm{T}$ cell response the number of $M$. hyopneumoniaespecific IFN- $\gamma$-SC was quantified in the PBMC of individual pigs. Pigs from the Vac3FLEX/Ch3 and VacMhp/ ChMhp groups had a significantly higher $(P<0.05)$ number of $M$. hyopneumoniae-specific IFN- $\gamma-\mathrm{SC}$ in their PBMC compared to the UnVac/Ch3 and UnVac/ChMhp groups between -14 to $28 \mathrm{dpc}$ (Fig. 4a).

$\mathrm{T}$ cell response was evaluated by comparing the number of PCV2-specific IFN- $\gamma$-SC. Pigs from the Vac3FLEX/Ch3 and VacPCV2/ChPCV2 groups had a significantly higher $(P<0.05)$ numbers of PCV2specific IFN- $\gamma-S C$ in their PBMC compared to the $\mathrm{UnVac} / \mathrm{Ch} 3$ and UnVac/ChPCV2 groups from - 14 to 28 dpc. Pigs from the UnVac/ChPCV2 group had a significantly higher $(P<0.05)$ numbers of $\mathrm{PCV} 2$-specific IFN- $\gamma$-SC in their PBMC compared to the UnVac/Ch3 at $28 \mathrm{dpc}$ (Fig. $4 \mathrm{~b}$ ).

The Vac3FLEX/Ch3 and VacPRRS/ChPRRSV groups had a significantly higher $(P<0.05)$ numbers of PRRSVspecific IFN- $\gamma$-SC in their PBMC compared to the UnVac/ Ch3 and UnVac/ChPRRSV groups from -14 to $14 \mathrm{dpc}$. The Vac3FLEX/Ch3, VacPRRS/ChPRRSV, and UnVac/ ChPRRSV groups had a significantly higher $(P<0.05)$ number of PRRSV-specific IFN- $\gamma$-SC in their PBMC compared to the UnVac/Ch3 group at $28 \mathrm{dpc}$ (Fig. 4c). The mean numbers of $M$. hyopneumoniae-, PCV2- and PRRSVspecific IFN- $\gamma-\mathrm{SC}$ in the UnVac/UnCh group remained at basal levels $\left(<20\right.$ cells $\left./ 10^{6} \mathrm{PBMC}\right)$ throughout the study.

\section{Pathology}

Pigs in the Vac3FLEX/Ch3 and VacMhp/ChMhp groups had significantly lower $(P<0.05)$ macroscopic lung lesion scores, microscopic mycoplasmal and interstitial lung lesion scores compared to the $\mathrm{UnVac} / \mathrm{Ch} 3$ group at 28 dpc. Pigs from the VacMhp/ChMhp group had significantly lower $(P<0.05)$ macroscopic lung lesion scores and microscopic mycoplasmal lung lesion scores compared to the UnVac/ChMhp group at $28 \mathrm{dpc}$ (Table 2).

Pigs from the Vac3FLEX/Ch3, VacPCV2/ChPCV2, and UnVac/ChPCV2 groups had significantly lower $(P<0.05)$ macroscopic lung lesion scores, microscopic mycoplasmal and interstitial lung lesion scores compared to the UnVac/ $\mathrm{Ch} 3$ group at $28 \mathrm{dpc}$. Pigs from the VacPCV2/ChPCV2 group had significantly lower $(P<0.05)$ microscopic interstitial lung lesion scores compared to the UnVac/ChPCV2 group at $28 \mathrm{dpc}$ (Table 2).

The Vac3FLEX/Ch3, VacPRRS/ChPRRSV, and UnVac/ ChPRRSV groups had significantly lower $(P<0.05)$ macroscopic lung lesion scores, microscopic mycoplasmal and interstitial lung lesion scores compared to the UnVac/Ch3 group at $28 \mathrm{dpc}$. The VacPRRS/ChPRRSV group had significantly lower $(P<0.05)$ macroscopic lung lesion scores and microscopic interstitial lung lesion scores compared to the UnVac/ChPRRSV group at $28 \mathrm{dpc}$. There were no 

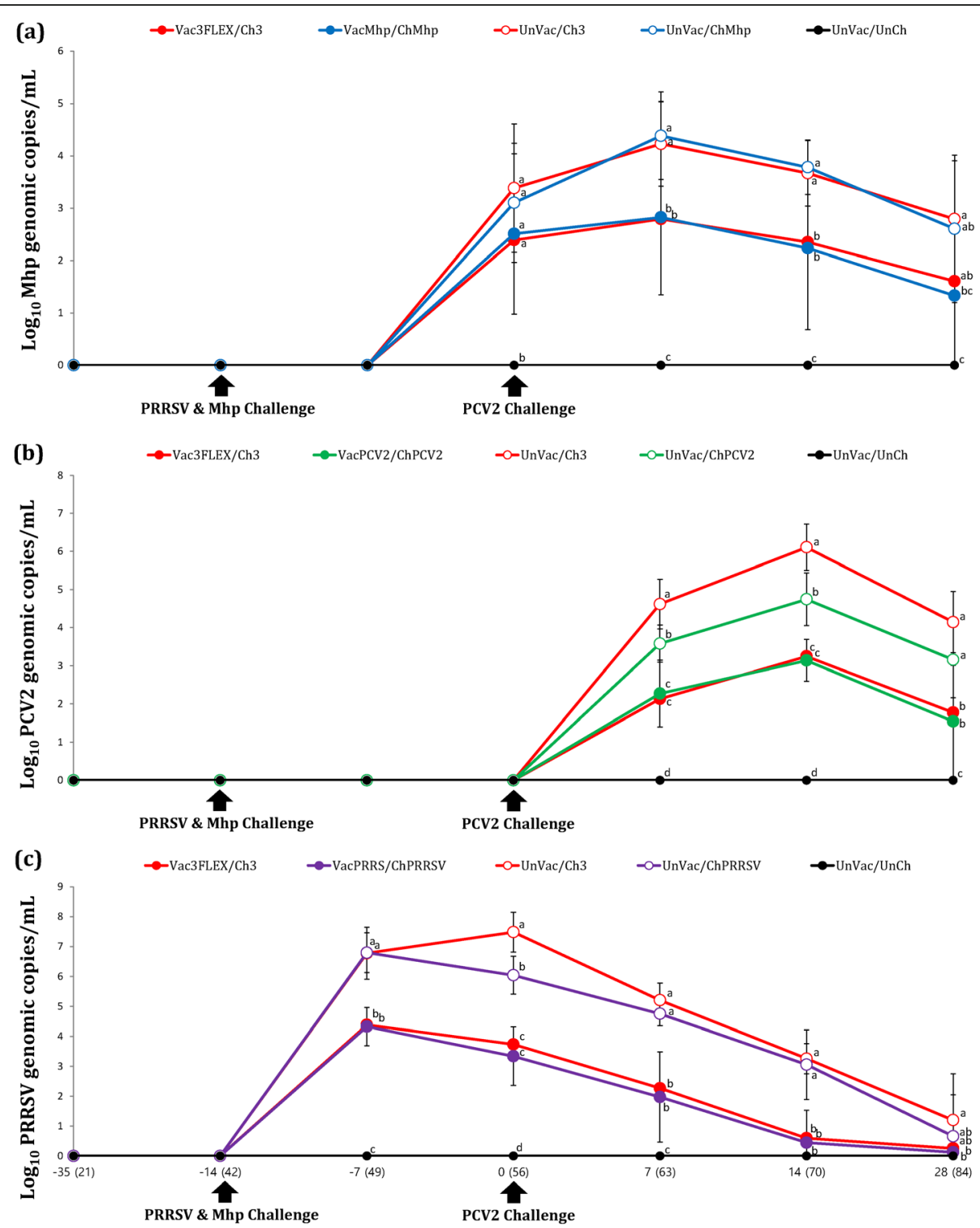

Days post challenge (Age, days)

Fig. 2 a Mean values of the genomic copy number of M. hyopneumoniae DNA in nasal swabs. $\mathbf{b}$ Mean values of the genomic copy number of PCV2 DNA in serum. c Mean values of the genomic copy number of PRRSV RNA in serum. Variation is expressed as the standard deviation. Different letters within a sampling point mean statistically significant differences $(P<0.05)$

macroscopic and microscopic lung lesions observed in pigs from the UnVac/UnCh group (Table 2).

\section{Discussion}

We have assessed the efficacy of a trivalent vaccine mixture against M. hyopneumoniae, PCV2, and PRRSV and compared it to the respective monovalent vaccinated and unvaccinated positive control groups. The trivalent vaccine mixture was able to reduce clinical signs, lung lesions, PRRSV and PCV2 viremia and improve weight gain compared to the unvaccinated positive control groups. The trivalent vaccine mixture, however, did not result in equal protection when compared against each respective monovalent vaccine, with the largest vaccine occurring within PRRSV. Although the PRRS vaccine in this study is widely used, an efficacious, commercially available PRRSV vaccine continues to be a global challenge, as PRRSV variant strains are continuously emerging from highly pathogenic outbreaks (particularly in Asia).

Pigs vaccinated with the trivalent vaccine following a triple challenge significantly improved their growth performance when compared to the unvaccinated control pigs. In contrast, growth performance was better but not significantly different between $M$. hyopneumoniae- 


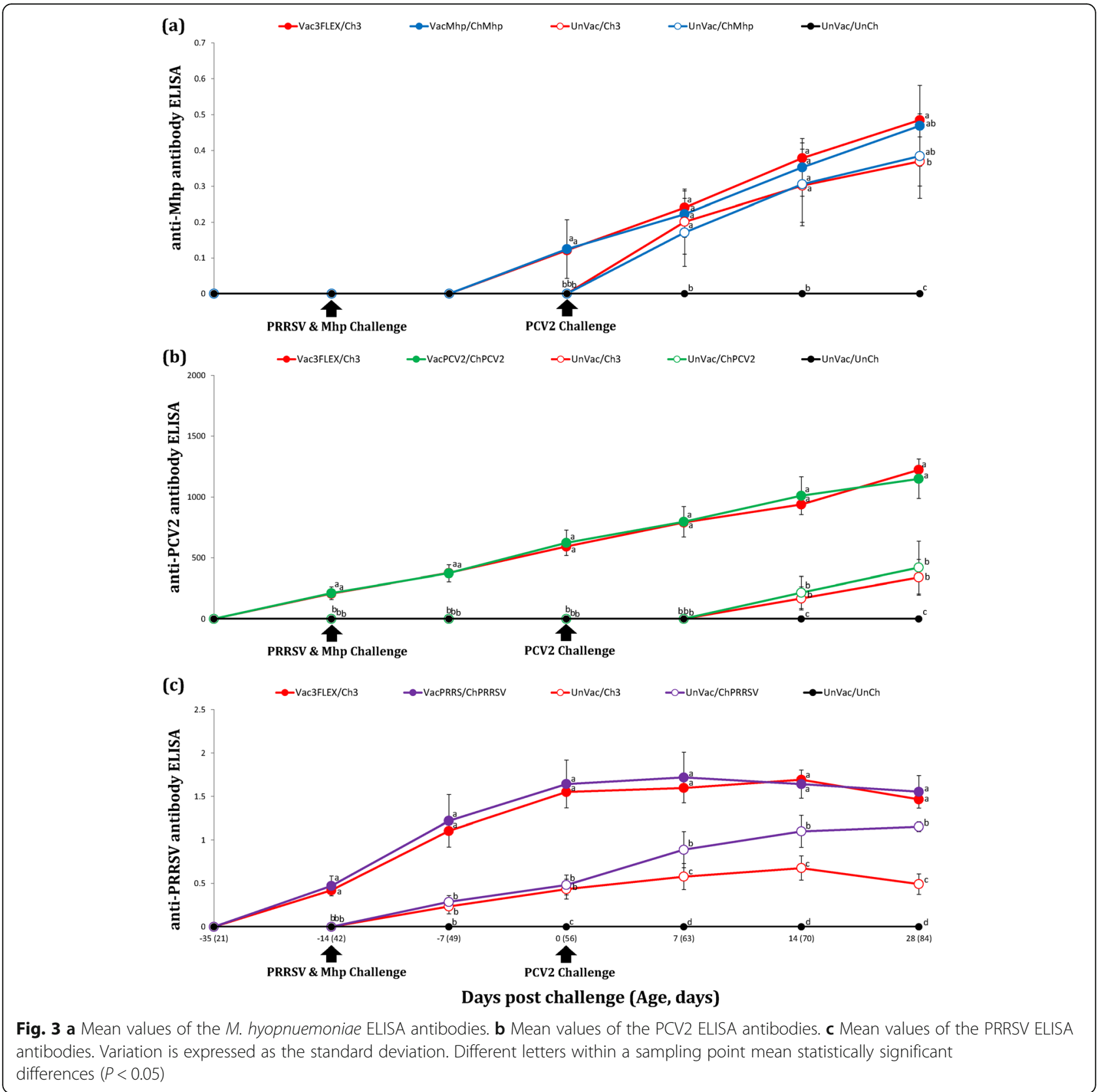

vaccinated and control pigs following M. hyopneumoniae challenge. These results are consistent with previous findings, where no significant difference on growth performance was observed between $M$. hyopneumoniae-vaccinated and unvaccinated pigs following an $M$. hyopneumoniae challenge [3, 4]. No significant difference on growth performance was also observed between PRRS-vaccinated and control pigs [5]. The possible reason for the lack of statistical significance could be that the growth performance of the pigs vaccinated with the monovalent vaccine was only evaluated for 6 weeks after a single challenge. In addition, growth retardation by a single challenge is likely not very severe. Therefore, the improvement on growth performance by the monovalent vaccines is not as drastic. A triple challenge is typically more severe than a single challenge. In addition, in a field study, infection with M. hyopneumoniae, PRRSV, and PCV2 increased the chance for opportunistic secondary bacterial infections which could result in further growth retardation. However, we did not observe a decrease in growth performance due to secondary bacterial infection in this experimental study. Taken together the results suggest that growth performance is an important parameter in 


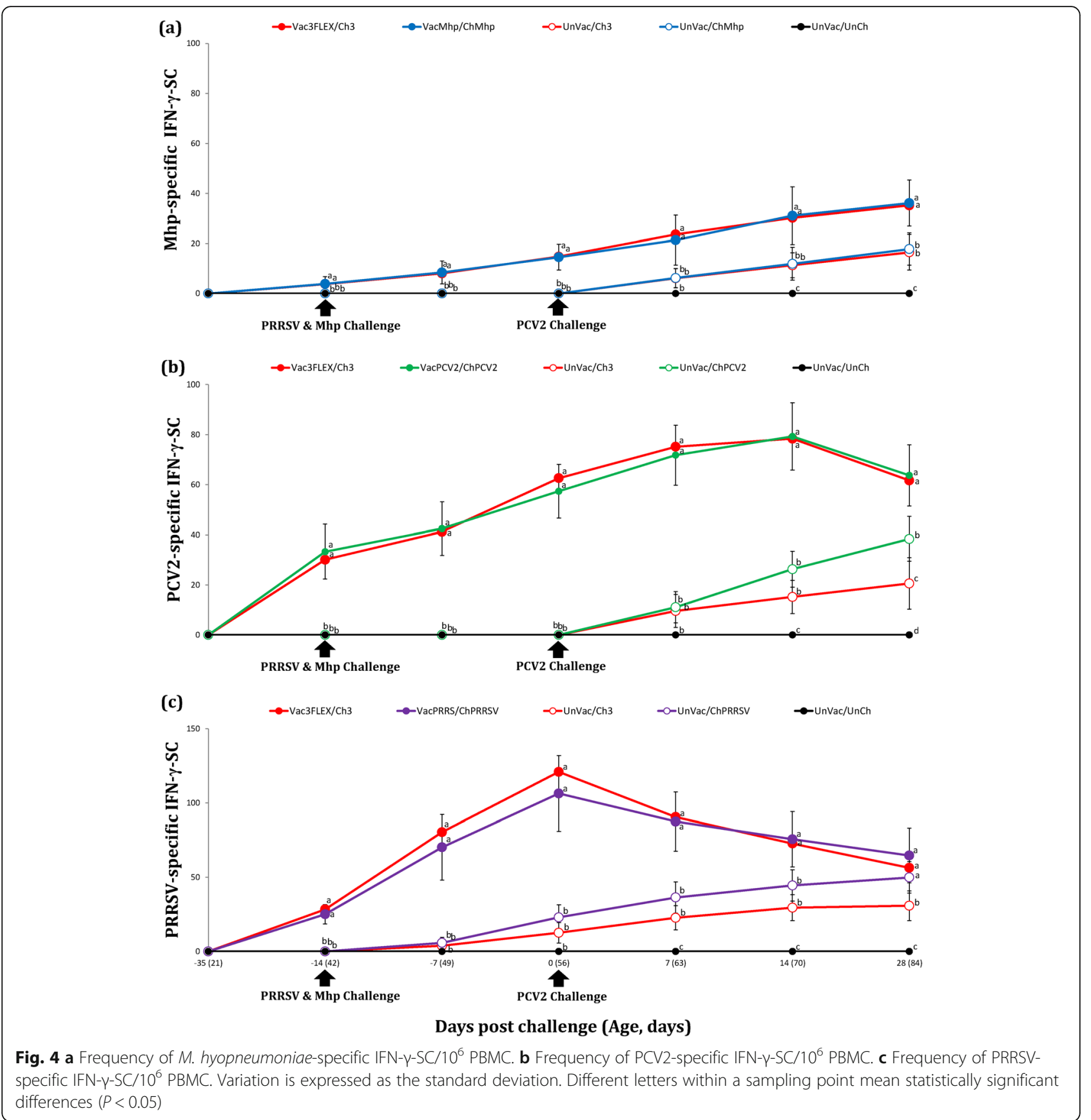

evaluating the trivalent vaccine mixture but not as important for evaluating the efficacy of the monovalent vaccines under experimental conditions.

PRDC cannot be controlled without controlling $M$. hyopneumoniae because $M$. hyopneumoniae infections exacerbate lung lesions caused by PRRSV and PCV2 in infected pigs $[6,7]$. In addition, previous work has shown that an $M$. hyopneumoniae vaccine can reduce interstitial pneumonia caused by PRRSV [8]. Therefore, control of M. hyopneumoniae is the first step to control PRDC caused by the three challenge pathogens used in this study. The trivalent vaccine mixture and monovalent $M$. hyopneumoniae vaccine were able to elicit similar numbers of $M$. hyopneumoniae-specific IFN- $\gamma$-SC in vaccinated pigs. This is important since, the cellmediated immunity as measured by IFN- $\gamma-\mathrm{SC}$ has been shown to play an important role in controlling M. hyopneumoniae infection $[9,10]$. Induction of cell-mediated immunity is also associated with a significant reduction in the amount of $M$. hyopneumoniae nasal shedding [11]. Vaccination with the trivalent product resulted in a comparable reduction of $M$. hyopneumoniae nasal 
Table 2 Lung lesion scores in trivalent vaccine mixture and respective monovalent vaccines

\begin{tabular}{|c|c|c|c|}
\hline \multirow[t]{2}{*}{ Groups } & \multirow{2}{*}{$\begin{array}{l}\text { Macroscopic } \\
\text { Lung lesion score }\end{array}$} & \multicolumn{2}{|l|}{ Microscopic } \\
\hline & & Mycoplasmal lesion score & Interstitial lesion score \\
\hline Vac3FLEX/Ch3 & $9 \pm 4.47^{b c}$ & $0.6 \pm 0.68^{b}$ & $0.9 \pm 0.64^{b}$ \\
\hline VacMhp/ChMhp & $5.75 \pm 4.94^{c d}$ & $0.4 \pm 0.50 \mathrm{bc}$ & $0.1 \pm 0.31^{c}$ \\
\hline UnVac/Ch3 & $42 \pm 11.11^{\mathrm{a}}$ & $3.5 \pm 0.71^{\mathrm{a}}$ & $3.3 \pm 0.82^{\mathrm{a}}$ \\
\hline UnVac/ChMhp & $12.5 \pm 6.35^{b}$ & $3.1 \pm 0.74^{\mathrm{a}}$ & $0.2 \pm 0.42^{c}$ \\
\hline UnVac/UnCh & $0.5 \pm 1.58^{d}$ & $0^{c}$ & $0.1 \pm 0.32^{c}$ \\
\hline Vac3FLEX/Ch3 & $9 \pm 4.47^{b}$ & $0.6 \pm 0.68^{b}$ & $0.9 \pm 0.64^{b}$ \\
\hline VacPCV2/ChPCV2 & $1.75 \pm 2.45^{c}$ & $0.05 \pm 0.22^{c}$ & $0.1 \pm 0.31^{c}$ \\
\hline UnVac/Ch3 & $42 \pm 11.11^{\mathrm{a}}$ & $3.5 \pm 0.71^{\mathrm{a}}$ & $3.3 \pm 0.82^{a}$ \\
\hline UnVac/ChPCV2 & $4.5 \pm 3.69 \mathrm{bc}$ & $0.2 \pm 0.42^{b c}$ & $0.9 \pm 0.57^{b}$ \\
\hline UnVac/UnCh & $0.5 \pm 1.58^{c}$ & $0^{c}$ & $0.1 \pm 0.32^{c}$ \\
\hline Vac3FLEX/Ch3 & $9 \pm 4.47^{b c}$ & $0.6 \pm 0.68^{b}$ & $0.9 \pm 0.64^{c}$ \\
\hline VacPRRS/ChPRRSV & $4.7 \pm 3.36^{c d}$ & $0.1 \pm 0.31^{c}$ & $0.25 \pm 0.44^{d}$ \\
\hline UnVac/Ch3 & $42 \pm 11.11^{\mathrm{a}}$ & $3.5 \pm 0.71^{\mathrm{a}}$ & $3.3 \pm 0.82^{a}$ \\
\hline UnVac/ChPRRSV & $11.5 \pm 6.69^{b}$ & $0.1 \pm 0.32^{b c}$ & $1.5 \pm 0.53^{b}$ \\
\hline UnVac/UnCh & $0.5 \pm 1.58^{d}$ & $0^{c}$ & $0.1 \pm 0.32^{d}$ \\
\hline
\end{tabular}

Different letters mean statistically significant differences within 5 groups $(P<0.05)$

shedding and lung lesions to that of the respective $M$. hyopneumoniae monovalent.

When comparing the efficacy between the trivalent vaccine mixture and the monovalent PCV2 vaccine, we looked at the cell-mediated immunity elicited by the PCV2 vaccines because it is an important immunity mechanism which contributes to the PCV2 clearance in the blood $[12,13]$. In addition, a positive correlation has been reported between PCV2 viremia and the severity of observed lesions $[12,14]$. Therefore, induction of IFN- $\gamma-$ $\mathrm{SC}$ and reduction of PCV2 viremia are the critical parameters in evaluating a PCV2 vaccine. In our study, there was no significant difference in the number of PCV2-specific IFN- $\gamma$-SC and reduction of PCV2 viremia between the trivalent vaccine mixture and monovalent PCV2 vaccine.

Lastly, we compared the efficacy of trivalent vaccine mixture against PRRSV with that of the monovalent PRRS vaccine and unvaccinated positive control. Reduction in viremia and lung lesions, and induction of cell-mediated immunity, specifically PRRSV-specific IFN- $\gamma$-SC which are used for the assessment of antigen-specific $\mathrm{T}$-cell responses in swine $[15,16]$ are important criteria for PRRSV vaccine evaluation. Despite the fact that the protective role of IFN- $\gamma-\mathrm{SC}$ is controversial [17], correlation between activation of $\mathrm{T}$ cell responses and clearance of PRRSV in blood has been previously reported $[18,19]$. These data suggest that $T$ cell responses elicited by PRRSV MLV vaccine play a role in the reduction of PRRSV viremia in vaccinatedchallenged pigs. In our study vaccination with either trivalent vaccine mixture or monovalent PRRS vaccine, both resulted in the induction of $\mathrm{T}$ cell responses and a reduction in the viral load in the blood simultaneously. In addition, there was no statistical difference in the number of PRRSV-specific IFN- $\gamma$-SC, levels of PRRSV viremia, and lung lesion scores between trivalent vaccination and monovalent vaccination in pigs.

In this study, we have presented evidence that a trivalent vaccine mixture is efficacious against challenge with three pathogens (M. hyopneumoniae, PCV2, and PRRSV) and it is similar to the efficacies of each individual monovalent vaccine against their respective single challenge. Additional interference studies would need to be conducted to establish this ratio and to determine compatibility of the trivalent vaccine mixture compared to the respective monovalent vaccines, especially in regard to the effect on the viability of PRRSV MLV vaccine. In addition, it is difficult to draw a full conclusion from the direct comparison with the respective monovalent vaccines, because of the different challenge inocula between the trivalent vaccine mixture group and the monovalent vaccine groups. Additional test groups of pigs vaccinated with monovalent vaccine followed by a triple challenge or vaccinated with the trivalent vaccine mixture followed by a single challenge with either $M$. hyopneumoniae, PCV2 or PRRSV should be included for further evaluation.

\section{Conclusions}

The results in this study demonstrate that the trivalent vaccine is significantly efficacious against a triple challenge 
of M. hyopneumoniae, PCV2, and PRRSV. The trivalent vaccine mixture, however, did not result in equal protection when compared against each respective monovalent vaccine, with the largest variance occurring within PRRSV.

\section{Methods}

\section{Pathogens}

Three challenge strains were used in this study. These included PRRSV strain SNUVR090851 (PRRSV-2, lineage 1, GenBank JN315685), M. hyopneumoniae strain SNU98703, and PCV2b strain SNUVR000463 (GenBank KF871068). Several key reasons played an important role in defining strain selection. The M. hyopneumoniae (strain SNU98703) produced lesions typical of M. hyopneumoniae found within the peribronchial and peribronchiolar lymphoid tissue hyperplasia in the lungs of infected pigs [20], while the PRRSV (strain SNUVR090851) caused interstitial pneumonia in the lungs of infected pigs [8], and the PCV2b (strain SNUVR000463) caused mild lymphoid depletion in the lymph nodes of infected pigs [21]. A triple challenge using M. hyopneumoniae (strain SNU98703), PRRSV (strain SNUVR090851), and PCV2b (strain SNUVR000463) also produced similar clinical symptoms [22].

\section{Animals}

The piglets used in this study were selected based on breeding herd negative serology screening for both PRRSV and M. hyopneumoniae prior to purchase. Long term clinical and slaughter history was also taken into account. Piglets selected for the study were 18-days-old at the time of purchase, colostrum-fed, and were Large White, Landrace, and Duroc crossbreds. The piglets were deemed to be clinically healthy upon arrival at 21 days of age. Piglets were screened and found seronegative for the following: PRRSV (IDEXX PRRS X3 Ab test, IDEXX Laboratories Inc., Westbrook, Maine, USA), $M$. hyopneumoniae ( $M$. hyo. Ab test, IDEXX Laboratories Inc.), PCV2 (PCV2 Ab Mono Blocking, Synbiotics, Lyon, France), and influenza A virus (Influenza A Ab test, IDEXX Laboratories Inc.). Serum samples were collected and tested for PCV2 and PRRSV by real-time polymerase chain reaction (PCR) [23]. Nasal swabs for $M$. hyopneumoniae were also collected and tested by real-time PCR [23]. All serum and nasal swabs produced negative results.

\section{Experimental design}

The random number generator function (Excel, Microsoft Corporation, Redmond, Washington, USA) was used to randomly divide 130 piglets into 9 groups (Table 3). A minimum sample size per each group was calculated as suggested by Cohen [24] using pwr package in $\mathrm{R}$ v.3.5.1 ( $\mathrm{R}$ Core Team: a language and environment for statistical computing. R Foundation for Statistical Computing, Vienna, Austria, http://www.r-project.org). A 0.05 significance level, 0.4 effect size, and $70 \%$ power were used to calculate the minimum number of piglets needed per group. This value was determined as 9.47, therefore, at least 10 piglets were designated per group.

Blinded personnel (defined as personnel who could not identify the vaccination status of the pigs) performed all actions including the administration of vaccines, administration of the PBS control, recorded observation and pulled defined measurements. The study was conducted at the Seoul National University, Department of Veterinary Pathology which contained a HEPA-filtered isolator. One room contained pigs from each group. The rooms each contained 10 pens with an individual pig housed per pen. Vaccinated groups were randomly assigned to each to include 20 pigs, 10 of which were female and 10 of which were male. These were further split into two rooms (10 pigs per room). Unvaccinated groups were assigned 10 pigs (5 male and 5 female) which were housed in a single room. The random number generator (Excel, Microsoft Corporation) was used to assign pigs to groups and rooms. Several key housing elements were taken into consideration such as both slatted and solid surface pen flooring, and rooms were lit for $12 \mathrm{~h} /$ day with the light intensity set to $40 \mathrm{~lx}$ in order to simulate daytime. The temperature in each room was also kept at a constant $22{ }^{\circ} \mathrm{C}$. Water was available for piglets to drink freely throughout the day via a nipple drinker which was placed in each pen. Each pen was additionally equipped with a self-feeder which provided access to a standard-balanced, age-appropriate, pelleted feed diet. Playtime stimulation was offered by placing a rubber ball in each pen.

At -35 days post challenge (dpc, 21 days old), pigs in the Vac3FLEX/Ch3 group were administered one dose ( $2 \mathrm{~mL}$ ) of 3FLEX (Boehringer Ingelheim Vetmedica) on the left side of the neck. The 3FLEX vaccine was prepared as follows: MycoFLEX (Serial no. 2730534A) and CircoFLEX (Serial no. 3091124A) were mixed together, and the mixture was then used to rehydrate Ingelvac PRRS MLV (Serial no. 2451180A). This was done in place of the Ingelvac PRRS MLV accompanying vaccine diluent and against the manufacturer's mixing directions. Pigs in the VacMhp/ChMhp, VacPCV2/ ChPCV2, and VacPRRS/ChPRRSV groups were administered one dose of MycoFLEX ( $1 \mathrm{~mL}$ ), CircoFLEX (1 $\mathrm{mL})$ and Ingelvac PRRS MLV $(2 \mathrm{~mL})$ respectively, on the left side of the neck. The pigs in the UnVac/Ch3, UnVac/ChMhp, UnVac/ChPCV2, UnVac/ChPRRSV, and $\mathrm{UnVac} / \mathrm{UnCh}$ groups were administered one dose $(1 \mathrm{~mL})$ of phosphate buffered saline (PBS, $0.01 \mathrm{M}, \mathrm{pH}$ 7.4) as a control. 
Table 3 Experimental design with vaccination and challenge strategies for PRRSV, M. hyopneumoniae (Mhp), and PCV2 at different days post-challenge (dpc)

\begin{tabular}{|c|c|c|c|c|}
\hline \multirow[t]{2}{*}{ Groups } & \multirow{2}{*}{$\begin{array}{l}\text { Vaccination (dpc) } \\
-35\end{array}$} & \multicolumn{2}{|c|}{ Challenge (dpc) } & \multirow{2}{*}{$\begin{array}{l}\text { Necropsy (dpc) } \\
28\end{array}$} \\
\hline & & -14 & 0 & \\
\hline Age (days) & 21 & 42 & 56 & 84 \\
\hline Vac3FLEX/Ch3 & 3FLEX & PRRSV/Mhp & PCV2 & 20 pigs \\
\hline VacMhp/ChMhp & MycoFLEX & Mhp & None & 20 pigs \\
\hline VacPCV2/ChPCV2 & CircoFLEX & None & PCV2 & 20 pigs \\
\hline VacPRRS/ChPRRSV & Ingelvac PRRS MLV & PRRSV & None & 20 pigs \\
\hline UnVac/Ch3 & None & PRRSV/Mhp & PCV2 & 10 pigs \\
\hline UnVac/ChMhp & None & Mhp & None & 10 pigs \\
\hline UnVac/ChPCV2 & None & None & PCV2 & 10 pigs \\
\hline UnVac/ChPRRSV & None & PRRSV & None & 10 pigs \\
\hline UnVac/UnCh & None & None & None & 10 pigs \\
\hline
\end{tabular}

At -14 dpc (42 days old), the pigs in the Vac3FLEX/ $\mathrm{Ch} 3$ and UnVac/Ch3 groups were challenged with two pathogens: PRRSV and M. hyopneumoniae. Three milliliters of the PRRSV inoculation containing $1.2 \times 10^{5}$ $50 \%$ tissue culture infective dose $\left(\mathrm{TCID}_{50}\right) / \mathrm{mL}$ was intranasal administered ( $1.5 \mathrm{~mL}$ per nostril). Five hours later pigs were anesthetized with a mixture of $2.2 \mathrm{mg} /$ kg xylazine hydrochloride (Rompun, Bayer Korea, Seoul, Korea) and $2.2 \mathrm{mg} / \mathrm{kg}$ tiletamine hydrochloride and $2.2 \mathrm{mg} / \mathrm{kg}$ zolazepam hydrochloride (Zoletil 50, Virbac Korea, Seoul, Korea) by intramuscular injection to prepare for the M. hyopneumoniae portion of the challenge. Pigs were then inoculated intratracheally with $7 \mathrm{~mL}$ (3.5 mL per nostril) of $M$. hyopneumoniae culture medium containing $10^{7}$ color changing units $(\mathrm{CCU}) / \mathrm{mL}$ as previously described $[25,26]$. This separation of challenges was done to avoid mixing of the two pathogens which could potentially affect their infectivity. Pigs in the VacPRRS/ChPRRSV and UnVac/ ChPRRSV groups were inoculated with the same lot of PRRSV and in the same way as described above, and pigs in the VacMhp/ChMhp and UnVac/ChMhp groups were inoculated with the same $M$. hyopneumoniae lot and in the same manner as described above.

At $0 \mathrm{dpc}$ (56 days old), pigs in the Vac3FLEX/Ch3, VacPCV2/ChPCV2, UnVac/Ch3, and UnVac/ChPCV2 groups were intranasally administered a $3 \mathrm{~mL}$ inoculum containing $1.2 \times 10^{5} \mathrm{TCID}_{50} / \mathrm{mL}$ of PCV2. Nasal swabs and blood samples were collected at $-35,-14,-7,0,7$, 14 , and $28 \mathrm{dpc}$ from all piglets. At $28 \mathrm{dpc}$ ( 84 days old), piglets were intravenously sedated with a $1 \mathrm{~mL} / 10 \mathrm{~kg}$ dose of sodium pentobarbital and were then euthanized by electrocution using a current of $110 \mathrm{~V}$ at a minimum frequency of $60 \mathrm{~Hz}$ for a minimum of $3 \mathrm{~s}$ [27]. Euthanized piglets were necropsied and tissues were collected and fixed for $24 \mathrm{~h}$ in $10 \%$ neutral buffered formalin, and embedded in paraffin.

\section{Clinical observations}

Pigs were monitored weekly post-challenge by blinded personnel for changes in physical conditions and clinical respiratory disease symptoms. Respiratory disease severity was scored on a scale ranging from 0 (normal) to 6 (severe dyspnea and abdominal breathing) as previously described [28].

\section{Average daily weight gain}

Pigs were measured for live weight at $-35 \mathrm{dpc}$ (21 days old), 0 dpc (56 days old), and $28 \mathrm{dpc}$ (84 days old). The average daily weight gain (ADWG; grams/pig/day) was analyzed over two time periods: (i) between -35 and 0 and (ii) between 0 and 28. ADWG was calculated as the difference between the starting and final weight divided by the duration of the stage. Data for dead or removed pigs were also included in the calculation.

\section{Quantification of PRRSV RNA in blood}

RNA was extracted from serum samples to assess PRRSV viremia, as previously described [23]. PRRSV genomic cDNA copies were quantified with real-time PCR for both the challenge and vaccine PRRSV strains [23].

\section{Quantification of $M$. hyopneumoniae DNA in nasal swabs} $M$. hyopneumoniaee genomic DNA copies were quantified by real-time PCR after DNA was extracted from nasal swabs using a commercial kit (QIAamp DNA Mini Kit, QIAGEN, Valencia, California, USA) [29].

\section{Quantification of PCV2 DNA in blood}

DNA extraction using a commercial kit (QIAamp DNA Mini Kit, QIAGEN) was performed followed by realtime PCR to quantify the PCV2 genomic DNA copy numbers from serum samples [29]. 


\section{Serology}

Serum samples were tested with ELISA kits for antibodies against the following: PRRSV (IDEXX PRRS X3 Ab test, IDEXX Laboratories Inc.), M. hyopneumoniae (M. hyo. Ab test, IDEXX Laboratories Inc.), PCV2 (PCV2 Ab Mono Blocking, Synbiotics), and influenza A virus (Influenza A Ab test, IDEXX Laboratories Inc.). Serum samples were considered positive for PRRSV and $M$. hyopneumoniae antibodies if the sample-to-positive $(\mathrm{S} / \mathrm{P})$ ratio was $\geq 0.4$, while serum samples were considered positive for influenza A virus if the sample-tonegative $(\mathrm{S} / \mathrm{N})$ ratio was $<0.6$, and serum samples were considered positive for PCV2 IgG antibody if the reciprocal ELISA titer was greater than 350 according to the manufacturer's instructions.

\section{Interferon- $\gamma$ secreting cells}

The numbers of PRRSV-, PCV2- and M. hyopneumoniaespecific interferon- $\gamma$ secreting cells (IFN- $\gamma-\mathrm{SC}$ ) were quantified in peripheral blood mononuclear cells (PBMC) as described by use of the PRRSV, PCV2 and M. hyopneumoniae challenge strains respectively $[3,6,15,30]$.

\section{Pathology}

Morphometric analysis of the macroscopic pulmonary lesion has been previously described [28]. Lungs were scored on a total scale of 100 points as follows: 10 points each to the right cranial lobe, right middle lobe, left cranial lobe, and left middle lobe, 27.5 points each to the right caudal lobe and left caudal lobe, and 5 points to the accessory lobe [28].

Microscopic pulmonary lesions were scored for interstitial pneumonia ranging from 0 (normal) to 6 (severe diffuse) [28]. Mycoplasmal pneumonia lesions were scored (0 to 6) based on the severity of peribronchiolar and perivascular lymphoid tissue hyperplasia [6]. All lung section scoring was performed by a blinded (defined by source of the sections) pathologist.

\section{Statistical analysis}

The experimental unit for analysis consisted of data collected from each individual piglet. One-way analysis of variance (ANOVA) and Kruskal-Wallis test were used in this study. ANOVA is a parametric statistical test to analyze the difference between group means, while the Kruskal Wallis test is a non-parametric analogue of ANOVA. ANOVA was used with variables that showed the following: normal distribution such as ADWG, PRRSV RNA, M. hyopneumoniae DNA, PCV2 DNA, PRRSV antibody titer, M. hyopneumoniae antibody titer, PCV2 antibody titer, and number of IFN- $\gamma-\mathrm{SC}$. The Kruskal-Wallis test was performed for variables without a normal distribution such as clinical signs, macroscopic lung lesion scores, and microscopic lung lesion scores.
When a significant difference existed between the groups, post hoc multiple comparison tests with Tukey's adjustment was conducted (t-test for ANOVA and ManWhitney test for Krustal-Wallis analysis) to determine the significant differences between the pairwise groups. A value of $P<0.05$ was considered significant.

\section{Abbreviations}

ADWG: Average daily weight gain; IFN- $\gamma$-SC: Interferon- $\gamma$ secreting cells; Mhp: Mycoplasma hyopneumoniae; PBMC: Peripheral blood mononuclear cells; PCV2: Porcine circovirus type 2; PRDC: Porcine respiratory disease complex; PRRSV: Porcine reproductive and respiratory syndrome virus

\section{Acknowledgements}

Not applicable.

\section{Authors' contributions}

TO and KHP performance of the experimental trials, data analysis and writing of the manuscript. SY, JJ, IK, and CP preparation of the inoculum and lab analysis, CC development of protocol, design of the study, review of the final manuscript, approval for publication. All authors read and approved the final manuscript.

\section{Funding}

The author's research was supported by contract research funds (Grant no. 550-20170104) of the Research Institute for Veterinary Science (RIVS) from the College of Veterinary Medicine and by the BK 21 Plus Program (Grant no. 5260-20150100) for Creative Veterinary Science Research. The funders had no role in study design, data collection, analysis and interpretation, decision to publish, or preparation of the manuscript.

\section{Availability of data and materials}

The datasets used and/or analysed during the current study are available from the corresponding author on reasonable request.

\section{Ethics approval and consent to participate}

All protocols strictly adhered to guidelines of the Ethical Animal Experiment of Seoul National University and were approved prior to this study by the Seoul National University Institutional Animal Care and Use and Ethics Committee.

\section{Consent for publication}

Not applicable.

\section{Competing interests}

The authors declare that they have no competing interests.

Received: 26 May 2018 Accepted: 16 September 2019

Published online: 16 October 2019

\section{References}

1. Chae C. Porcine respiratory disease complex: interaction of vaccination and porcine circovirus type 2, porcine reproductive and respiratory syndrome virus, and Mycoplasma hyopneumoniae. Vet J. 2016;212:1-6.

2. Thacker EL. Porcine respiratory disease complex what is and why does it remain a problem? Pig J. 2001;48:66-70.

3. Arsenakis L, Panzavolta L, Michiels A, Del Pozo SR, Boyen F, Haesebrouck F, Maes D. Efficacy of Mycoplasma hyopneumoniae vaccination before and at weaning against experimental challenge infection in pigs. BMC Vet Res. 2016;12:63.

4. Michiels A, Arsenakis I, Boyen F, Krejci R, Haesebrouck F, Maes D. Efficacy of one dose vaccination against experimental infection with two Mycoplasma hyopneumoniae strains. BMC Vet Res. 2017;13(1):274.

5. Schweer WP, Schwartz K, Burrough ER, Yoon KJ, Sparks JC, Gabler NK. The effect of porcine reproductive and respiratory syndrome and porcine epidemic diarrhea virus challenge on growing pigs I: growth performance and digestibility. J Anim Sci. 2016;94(2):514-22.

6. Thacker EL, Halbur PG, Ross RF, Thanawongnuwech R, Thacker BJ. Mycoplasma hyopneumoniae potentiation of porcine reproductive and respiratory syndrome virus-induced pneumonia. J Clin Microbiol. 1999;37(3):620-7. 
7. Opriessnig T, Thacker EL, Yu S, Fenaux M, Meng XJ, Halbur PG. Experimental reproduction of postweaning multisystemic wasting syndrome in pigs by dual infection with Mycoplasma hyopneumoniae and porcine circovirus type 2. Vet Pathol. 2004:41(6):624-40.

8. Han K, Seo HW, Oh Y, Kang I, Park C, Chae C. Comparison of the virulence of European and north American genotypes of porcine reproductive and respiratory syndrome virus in experimentally infected pigs. Vet J. 2013;195:313-8.

9. Djordjevic SP, Eamens GJ, Romalis LF, Nicholls PJ, Taylor V, Chin J. Serum and mucosal antibody responses and protection in pigs vaccinated against Mycoplasma hyopneumoniae with vaccines containing a denatured membrane antigen pool and adjuvant. Aust Vet J. 1997;75(7):504-11.

10. Thacker EL, Thacker BJ, Kuhn M, Hawkins PA, Waters WR. Evaluation of local and systemic immune responses induced by intramuscular injection of a Mycoplasma hyopneumoniae bacterin to pigs. Am J Vet Res. 2000;61(11):1384-9.

11. Park C, Jeong J, Choi K, Chae C. Efficacy of a new bivalent vaccine of porcine circovirus type 2 and Mycoplasma hyopneumoniae (Fostera'MPCV MH) under experimental conditions. Vaccine. 2016;34(2):270-5.

12. Meerts P, Van-Gucht S, Cox E, Vandebosch A, Nauwynck HJ. Correlation between type of adaptive immune response against porcine circovirus type 2 and level of virus replication. Viral Immunol. 2005;18(2):333-41.

13. Fort M, Fernandes LT, Nofrarias M, Díaz I, Sibila M, Pujols J, Mateu E, Segalés J. Development of cell-mediated immunity to porcine circovirus type 2 (PCV2) in caesarean-derived, colostrum-deprived piglets. Vet Immunol Immunopathol. 2009;129(1-2):101-7.

14. Meerts P, Misinzo G, Lefebvre D, Nielsen J, Bøtner A, Kristensen CS, Nauwynck $\mathrm{HJ}$. Correlation between the presence of neutralizing antibodies against porcine circovirus 2 (PCV2) and protection against replication of the virus and development of PCV2-associated disease. BMC Vet Res. 2006;2:6-16.

15. Meier WA, Galeota J, Osorio FA, Husmann RJ, Schnitzlein WM, Zuckermann FA. Gradual development of the interferon-gamma response of swine to porcine reproductive and respiratory syndrome virus infection or vaccination. Virology. 2003;309(1):18-31.

16. Foss DL, Zilliox MJ, Meier W, Zuckermann F, Murtaugh MP. Adjuvant danger signals increase the immune response to porcine reproductive and respiratory syndrome virus. Viral Immunol. 2002;15(4):557-66.

17. Xiao Z, Batista L, Dee S, Halbur P, Murtaugh MP. The level of virus-specific $\mathrm{T}$ - cell and macrophage recruitment in porcine reproductive and respiratory syndrome virus infection in pigs is dependent of virus load. J Virol. 2004; 78(11):5923-33.

18. Kimman TG, Cornelissen LA, Moormann RJ, Rebel JM, Stockhofe-Zurwieden N. Challenges for porcine reproductive and respiratory syndrome virus (PRRSV) vaccinology. Vaccine. 2009;27(28):3704-18.

19. Murtaugh MP, Genzow M. Immunological solutions for treatment and prevention of porcine reproductive and respiratory syndrome (PRRS). Vaccine. 2011;29(46):8192-204.

20. Kwon D, Choi C, Chae C. Chronologic localization of Mycoplasma hyopneumoniae in experimental infected pigs. Vet Pathol. 2002;39(5):584-7.

21. Seo HW, Park C, Han K, Chae C. Effect of porcine circovirus type 2 (PCV2) vaccination on PCV2-viremic piglets after experimental PCV2 challenge. Vet Res. 2014;45:13.

22. Jeong J, Kang I, Kim S, Park KH, Park C, Chae C. Comparison of 3 vaccination strategies against porcine reproductive and respiratory syndrome virus, Mycoplasma hyopneumoniae, and porcine circovirus type 2 on a 3 pathogen challenge model. Can J Vet Res. 2018;82(1):39-47.

23. Wasilk A, Callahan JD, Christopher-Hennings J, Gay TA, Fang Y, Dammen M, Reos ME, Torremorell M, Polson D, Mellencamp M, Nelson E, Nelson WM. Detection of U.S., Lelystad, and European-like porcine reproductive and respiratory syndrome viruses and relative quantitation in boar semen and serum samples by real-time PCR. J Clin Microbiol. 2004;42(10):4453-61.

24. Cohen J. Statistical power analysis for the behavioral science. 2 nd ed. New York: Routledge; 1988. p. 273-406.

25. Van Reeth $\mathrm{K}$, Nauwynck H, Pensaert M. A potential role for tumour necrosis factor-a in synergy between porcine respiratory coronavirus and bacterial lipopolysaccharide in the induction of respiratory disease in pigs. J Med Microbiol. 2000;49(7):613-20.

26. Marchioro SB, Sacristan RDP, Michiels A, Haesebrouck F, Conceição FR, Dellagostin $O A$, Maes $D$. Immune responses of a chimeric protein vaccine containing Mycoplasma hyopneumoniae antigens and LTB against experimental M. hyopneumoniae infection in pigs. Vaccine. 2014;32(36):4689-94.
27. Beaver BV, Reed W, Leary S, McKiernan B, Bain F, Schultz R, Bennett BT. Pascoe p, Shull E, Cork LC, Francis-Floyd R, amass KD, Johnson R, Schmidt $\mathrm{RH}$, Uderwood W, Thornton GW, Kohn B. 2000 report of the AVMA panel on euthanasia. J Am Vet Med Assoc. 2001;218(5):669-96.

28. Halbur PG, Paul PS, Frey ML, Landgraf J, Eernisse K, Meng XJ, Lum MA, Andrews JJ, Rathje JA. Comparison of the pathogenicity of two US porcine reproductive and respiratory syndrome virus isolates with that of the Lelystad virus. Vet Pathol. 1995;32(6):648-60.

29. Gagnon CA, del Castillo JR, Music N, Fontaine G, Harel J, Tremblay D. Development and use of a multiplex real-time quantitative polymerase chain reaction assay for detection and differentiation of Porcine circovirus-2 genotypes $2 \mathrm{a}$ and $2 \mathrm{~b}$ in an epidemiological survey. J Vet Diagn Investig. 2008;20(5):545-58.

30. Diaz I, Darwich L, Pappaterra G, Pujols J, Mateu E. Immune responses of pigs after experimental infection with a European strain of porcine reproductive and respiratory syndrome virus. J Gen Virol. 2005;86(pt 7):1943-51.

\section{Publisher's Note}

Springer Nature remains neutral with regard to jurisdictional claims in published maps and institutional affiliations.
Ready to submit your research? Choose BMC and benefit from:

- fast, convenient online submission

- thorough peer review by experienced researchers in your field

- rapid publication on acceptance

- support for research data, including large and complex data types

- gold Open Access which fosters wider collaboration and increased citations

- maximum visibility for your research: over $100 \mathrm{M}$ website views per year

At BMC, research is always in progress.

Learn more biomedcentral.com/submissions 